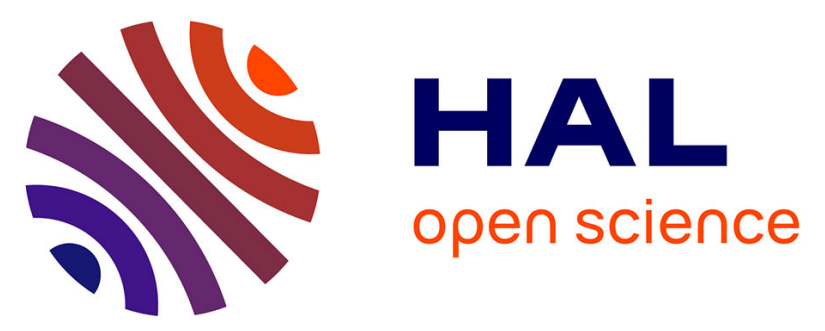

\title{
Atmospheric Plasma-Enhanced Spatial Chemical Vapor Deposition of SiO 2 Using Trivinylmethoxysilane and Oxygen Plasma
}

Viet Huong Nguyen, Abderrahime Sekkat, César Arturo Masse de La Huerta, Fadi Zoubian, Chiara Crivello, Juan Rubio-Zuazo, Moustapha Jaffal, Marceline Bonvalot, Christophe Vallée, Olivier Aubry, et al.

\section{To cite this version:}

Viet Huong Nguyen, Abderrahime Sekkat, César Arturo Masse de La Huerta, Fadi Zoubian, Chiara Crivello, et al.. Atmospheric Plasma-Enhanced Spatial Chemical Vapor Deposition of SiO 2 Using Trivinylmethoxysilane and Oxygen Plasma. Chemistry of Materials, 2020, 32 (12), pp.5153-5161. 10.1021/acs.chemmater.0c01148 . hal-02917572

\section{HAL Id: hal-02917572 \\ https://hal.univ-grenoble-alpes.fr/hal-02917572}

Submitted on 7 Jan 2021

HAL is a multi-disciplinary open access archive for the deposit and dissemination of scientific research documents, whether they are published or not. The documents may come from teaching and research institutions in France or abroad, or from public or private research centers.
L'archive ouverte pluridisciplinaire HAL, est destinée au dépôt et à la diffusion de documents scientifiques de niveau recherche, publiés ou non, émanant des établissements d'enseignement et de recherche français ou étrangers, des laboratoires publics ou privés. 


\title{
Atmospheric Plasma-Enhanced Spatial Chemical Vapor Deposition of $\mathrm{SiO}_{2}$ using Trivinylmethoxysilane and Oxygen Plasma
}

\author{
Viet Huong Nguyen, ${ }^{1 *}$ Abderrahime Sekkat, ${ }^{2}$ César Arturo Masse de la Huerta, ${ }^{2}$ Fadi Zoubian, ${ }^{3}$ Chi- \\ ara Crivello, ${ }^{2}$ Juan Rubio-Zuazo, ${ }^{4,5}$ Moustapha Jaffal, 6 Marceline Bonvalot, ${ }^{6}$ Christophe Vallée, ${ }^{6}$ Oliv- \\ ier Aubry, ${ }^{3}$ Hervé Rabat, ${ }^{3}$ Dunpin Hong, ${ }^{3}$ and David Muñoz-Rojas ${ }^{*}, 2$ \\ ${ }^{1}$ Faculty of Electrical and Electronic Engineering, Phenikaa University, Hanoi 12116, Vietnam \\ ${ }^{2}$ Université Grenoble Alpes, CNRS, Grenoble INP, LMGP, Grenoble, France \\ ${ }^{3}$ GREMI, UMR 6606 CNRS-Universite d'Orléans, BP 6744, 45067 Orléans Cedex 2, France \\ ${ }^{4}$ Spanish CRG BM25-SpLine Beamline at the ESRF, 71 Av des Martyrs CS 40220, 38043 Grenoble Cedex 9, France \\ ${ }^{5}$ Instituto de Ciencia de Materiales de Madrid-CSIC, Sor Juana Inés de la Cruz, 3, Cantoblanco, 28049 Madrid, Spain \\ ${ }^{6}$ LTM, CNRS, 17 avenue des Martyrs 38045, Grenoble, France
}

\begin{abstract}
SiO}_{2}$ constitutes one of the most widely used dielectric materials in microelectronics, packaging and optical industries. Therefore, the development of new processes to deposit $\mathrm{SiO}_{2}$ at low temperature and in an affordable and scalable way are desirable. In this work, we present a low-temperature, open-air process based on spatial atomic layer deposition (SALD) that yields high purity $\mathrm{SiO}_{2}$ films at temperatures down to room temperature. The films were obtained by operating our SALD system in CVD mode (i.e. allowing precursor crosstalk), using an oxygen plasma in combination with Trivinylmethoxysilane (TVMS). TVMS is an appealing precursor since it is highly volatile, affordable and does not contain halogen elements, thus being very suitable for application in atmospheric-pressure spatial deposition systems. Conversely, water, oxygen, hydrogen peroxide or ozone did not show any reactivity with TVMS at temperatures up to $260^{\circ} \mathrm{C}$. Thus, when operating our system in ALD mode, no film could be obtained due to the lack of reactivity of the precursor with $\mathrm{OH}^{*}$ surface groups. 3D printing was employed to fabricate custom heads integrating both the precursor injector and the atmospheric plasma generator. Our results show that compact, conformal, pinhole-free $\mathrm{SiO}_{2}$ thin films can be deposited by our atmospheric plasma-enhanced spatial chemical vapor deposition (APE-SCVD) approach at low temperatures $\left(\mathrm{RT}-180{ }^{\circ} \mathrm{C}\right)$ on different substrates, including silicon wafers, micro-glass slides, or even on polymeric substrates with a high growth rate up to $2-5$ $\mathrm{nm} / \mathrm{min}$. The deposition rate increased when increasing the power applied to the plasma reactor but decreased when increasing the deposition temperature due to de faster decay of the metastable oxygen radical species. FTIR results showed no differences for films deposited with different plasma powers. Conversely, temperature had an effect on the ratio between the $\mathrm{AS}_{1}$ and $\mathrm{AS}_{2}$ bands. Even though the deposition of $\mathrm{SiO}_{2}$ was carried out at low temperatures in the open air using a metalorganic precursor, no contamination from $\mathrm{SiN}_{\mathrm{x}}$ or $\mathrm{SiC}_{\mathrm{x}}$, was observed by FTIR and XPS measurements. Our results open the door to the low-temperature, fast printing of Si-based devices.
\end{abstract}

\section{INTRODUCTION}

Silicon dioxide $\left(\mathrm{SiO}_{2}\right)$ is used in various fields such as microelectronics, packaging, or optical communication due to its excellent physical properties including corrosion resistance, dielectric nature, optical transparency, hardness, gas and humidity barrier, etc. ${ }^{1-3} \mathrm{SiO}_{2}$ thin films can be obtained using various techniques, including chemical vapor deposition (CVD), ${ }^{4,5}$ plasma-enhanced chemical vapor deposition (PECVD), ${ }^{6-8}$ atomic layer deposition (ALD) ${ }^{9-11}$ and physical techniques such as thermal oxidation, ${ }^{12}$ magnetron sputtering, ${ }^{13}$ among others. For most of the mentioned techniques, $\mathrm{SiO}_{2}$ deposition is usually performed at low pressure in a vacuum-chamber, which has a substantial repercussion on the cost of scaling up to industrial applications. Developing alternative approaches for the open-air deposition of Si- based thin films at low temperatures and with high throughput is therefore desirable.

Recently, Atmospheric pressure spatial ALD (AP-SALD) has become an appealing alternative to conventional ALD, in that it allows deposition of highly conformal and uniform films even in the open atmosphere and with ultrafast deposition rates (up to two orders of magnitude faster than standard ALD). ${ }^{14-16}$ In addition, AP-SALD can be easily scaled up to large surfaces, since no vacuum chamber is needed. As a result, AP-SALD has been widely applied to the deposition of functional materials for new generation photovoltaics, ${ }^{17-20}$ or for the encapsulation of flexible electronics. $^{21-24}$ Similar to conventional ALD and CVD processes, plasma activation of SALD has been already demonstrated by using atmospheric pressure plasmas. ${ }^{25,26}$ 
In open-air SALD approaches, a gas manifold injector is used and placed very close to the substrate to avoid crosstalk of precursors across the inert gas barriers. ${ }^{27,28}$ The deposition area is thus only related to the size of the gas injector and its scanning amplitude over the substrate. While such approach was designed to perform ALD, the distance between the substrate and the injector (deposition gap) can be increased to facilitate the crosstalk of precursors in the gas phase, resulting in film deposition via CVD mode. ${ }^{28-30}$ This so-called spatial chemical vapor deposition (SCVD) mode allows depositing films with higher growth rates as compared to SALD while still retaining the main advantages of the latter, i.e. operating at low temperatures and in open air, as well as film quality and conformality inherent to ALD. ${ }^{28}$ Furthermore, similar atmospheric plasma generators used in spatial reactors could also be used in SCVD mode, thus allowing more flexibility in processing conditions, such as a low deposition temperatures $\left(<100^{\circ} \mathrm{C}\right)$ or a wider choice of precursors. The combination of atmospheric plasma generator and the SCVD technique would therefore be particularly beneficial to industrial-scale applications, such as for instance deposition of thin films for solar cells, barrier coatings, or layers for electronic device encapsulation. ${ }^{31,32}$

So far, the most used precursors for the chemical vapor deposition of $\mathrm{SiO}_{2}$ thin films are silane $\left(\mathrm{SiH}_{4}\right)$ and halogencontaining precursors, such as $\mathrm{SiCl}_{4}{ }^{33,34}, \mathrm{Si}_{2} \mathrm{Cl}_{6}{ }^{35}$ or $\mathrm{SiH}_{2} \mathrm{Cl}_{2}{ }^{36}$ because of their ability to provide high-purity films. The fabrication of $\mathrm{SiO}_{2}$ films using these conventional precursors is often carried out at relatively high temperatures $\left(>400^{\circ} \mathrm{C}\right)$. A manner to reduce the deposition temperature is to employ catalysts such as $\mathrm{NH}_{3}$ or pyridine. ${ }^{37,38}$ Although the halogen-containing precursors are highly volatile and reactive, they are also pyrophoric and their use in $\mathrm{SiO}_{2}$ fabrication produces corrosive gases. When considering the safety, toxicity, and compatibility with open-air low-cost chemical vapor deposition approaches, halide-free metalorganic precursors such as tetraethoxysilane (TEOS), 5,6,39-42 tetramethylsilane (TMS) ${ }^{43,44}$, di-isopropylaminosilane (DIPAS) ${ }^{45,46}$ or tris(dimethylamino)silane (TDMAS) ${ }^{47}$ are indeed more attractive choices. Another potential candidate is trivinylmethoxysilane (TVMS) because of its high vapor pressure, non-toxicity and appealing cost. These qualities make TVMS very appealing in particular for use in atmospheric-pressure chemical vapor deposition systems. However, Burton et al. have demonstrated that this precursor is indeed not suitable for ALD due to its low reactivity towards $\mathrm{SiOH}^{*}$ surfaces, as well as $\mathrm{H}_{2} \mathrm{O}$ in the range of temperatures up to 400 ${ }^{\circ} \mathrm{C} .47$ Moreover, although a recent theoretical study by Vajeeston et al. indicates that TVMS should be a suitable candidate for the deposition of Si by ALD, to the best of our knowledge, this precursor has never been successfully used for both $\mathrm{SiO}_{2}$ and $\mathrm{Si}$ thin film deposition via chemical vapor deposition techniques.

In this work, we have used an atmospheric plasma-enhanced spatial chemical vapor deposition (APE-SCVD) approach to deposit $\mathrm{SiO}_{2}$ thin films at low temperatures (RT $\left.180{ }^{\circ} \mathrm{C}\right)$ in open air with high deposition rates $(2-5$ $\mathrm{nm} / \mathrm{min}$ ), on different substrates including glass slides, silicon wafers or flexible polymeric substrates. We have used a custom-designed and 3D printed one-block gas injection head incorporating the atmospheric plasma generator. In such a configuration, a confined reaction zone is obtained, limited to the volume where the different precursors can meet over the substrate surface. This mixing zone is considered as a virtual CVD chamber whose volume can be easily controlled by modifying the injector-substrate gap. This enables more flexibility in controlling the growth rate, the roughness as well as the density of the deposited films. Trivinylmethoxysilane (TVMS) has been successfully used for the first time as a silicon precursor to deposit $\mathrm{SiO}_{2}$ thin films with oxygen plasma as a co-reactant. The effect of different parameters on the $\mathrm{SiO}_{2}$ film quality, including substrate temperature, oxygen plasma power, the gap between the substrate and the injection head, as well as the influence of the head design on the film quality is presented and discussed. Our work demonstrates that the spatial separation concept can also be applied to CVD reactors even when using plasma activation.

\section{EXPERIMENTS AND PROCEDURE}

\section{Thin film deposition}

Different depositions were performed in a home-build APESALD system equipped with a close-proximity manifold head. As described previously, by adjusting different parameters, the system can operate in a CVD mode, ${ }^{30}$ while still showing a constant growth per cycle (GPC) and a high conformality. ${ }^{29}$ Trivinylmethoxysilane $\left(\mathrm{Si}\left(\mathrm{C}_{2} \mathrm{H}_{3}\right)_{3}\left(\mathrm{OCH}_{3}\right)\right.$, TVMS, used as received from Fluorochem) was used as the silicon precursor, while oxygen plasma was employed as the oxidizing agent. The latter was produced using a homebuilt dielectric barrier discharge (DBD) plasma source, which contains two interdigitated copper grids and a fused quartz layer of $2 \mathrm{~mm}$-thick in between as dielectric barrier. ${ }^{48}$ The DBD source was integrated in a custom-designed deposition head that was fabricated by 3D printing using a Formlabs II 3D printer. The precursor bubbler was kept at room temperature. TVMS was delivered to the substrate by bubbling a $50 \mathrm{sccm}$ nitrogen gas flow through the liquid precursor, which was then diluted with an extra nitrogen flow (100 sccm) before being sent to the injection head. The oxygen plasma was generated by delivering $200 \mathrm{sccm}$ of pure oxygen to the DBD plasma source. The maximum voltage and frequency that can be applied to the DBD are $12 \mathrm{kV}$ and $10 \mathrm{kHz}$, respectively. The silicon substrates and micro-glass slides used in this work were cleaned using ethanol, deionized water, and then dried under pure nitrogen. On samples used for TVMS surface reactivity tests, an extra 2 min long oxygen plasma cleaning-for $2 \mathrm{~min}$ was employed to functionalize the substrate surface before exposing it to TVMS.

\section{Characterization}

The oxygen plasma was characterized by using a high-resolution optical emission spectroscopy (OES) system (SpectraPro HRS 750 from Princeton Instruments). The spectrum was obtained (in the dark) by pointing an optical fiber toward the DBD plasma source while oxygen was being injected.

The chemical composition of the deposited films was analysed by using Fourier Transform Infrared spectroscopy 
(FTIR, Bruker VERTEX 70v) and X-ray Photoelectron Spectroscopy (XPS). XPS measurements were performed at BM25-SpLine laboratory using a standard ultra-high vacuum chamber with a pressure of $1 \times 10^{-10}$ mbar. A hemispherical analyzer equipped with a channel-plate and a non-monochromatic Mg X-ray source ( $h v=1254.6 \mathrm{eV}$ ) were used for the measurements. The energy scale was calibrated with the C1s line from contamination carbon at $284.8 \mathrm{eV}$. Analyses were carried out at a constant angle of $90^{\circ}$ between the sample surface and the analyzer. The thickness, surface morphology, and mass density of deposited films were analyzed by ellipsometry (Film Sense FS-1), Xray reflectometry (D500 Siemens, using $\mathrm{Cu} K \alpha$ radiation $(\lambda$ $=0.15406 \mathrm{~nm}), 0.01 \% / \mathrm{step}, 2 \mathrm{~s} / \mathrm{step}$ ) and field emission gun-scanning electron microscopy (FEG-SEM Environmental FEI Quanta 250).

\section{Simulation}

A combination of three modules from Comsol Multiphysics was used for 2D simulation: heat transfer in fluids, laminar flow and transport of diluted species. The gas injector/substrate distance and the gas flow per outlet were kept at 150 or $500 \mu \mathrm{m}$ and $100 \mathrm{sccm}$, respectively.

\section{RESULTS AND DISCUSSION}

As a first step, the reactivity of TVMS precursor with respect to different oxidizing agents and various substrates was investigated. As stated above, Vajeeston et al. ${ }^{49}$ have used state-of-the-art density-functional calculations to predict that TVMS should be a suitable precursor for the ALD growth of $\mathrm{Si}$ and $\mathrm{SiO}_{2}$ thin films because of a favorable surface adsorption on an $-\mathrm{OH}^{*}$ terminated surface, and reaction of the precursor with itself in the case of $\mathrm{Si}$ deposition. ${ }^{49}$ However, to our best knowledge, there are no reports in which TVMS has been successfully used to deposit $\mathrm{SiO}_{2}$ or $\mathrm{Si}$ thin films by CVD or ALD techniques. In addition, Burton et $a l^{47}$ have used a conventional ALD reactor and FTIR to experimentally demonstrate that $\mathrm{Si}-\mathrm{OCH}_{3}$ bonds are relatively inert towards $\mathrm{Si}-\mathrm{OH}^{*}$ surface groups, while breaking $\mathrm{Si}-\mathrm{C}$ bonds to form $\mathrm{Si}-\mathrm{O}$ bonds may have an activation barrier that is kinetically limiting.

Thus, the ALD reactivity of TVMS with micro-glass slides, silicon substrates or oxygen plasma-treated silicon substrates has been tested, as well as its reactivity
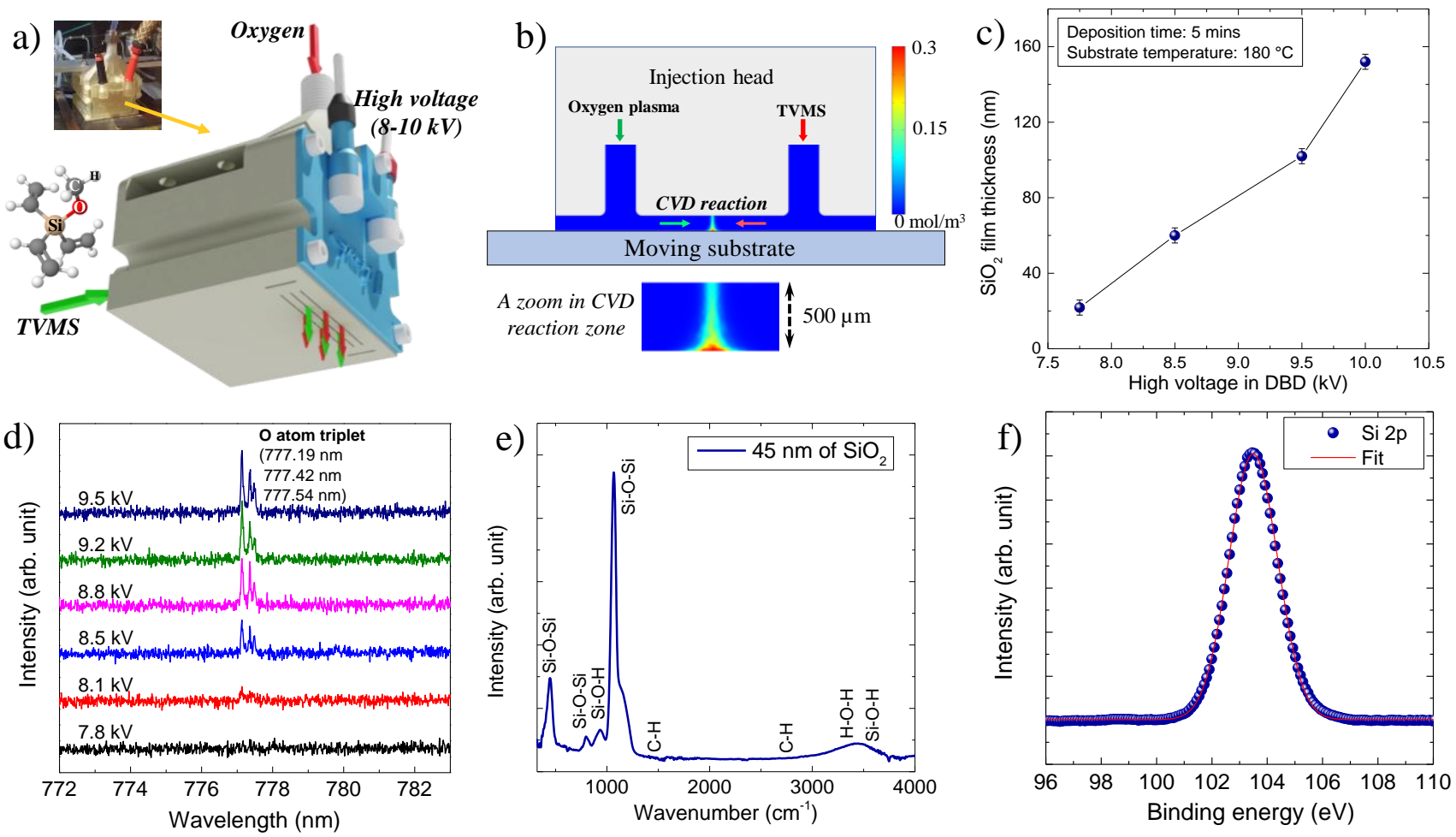

Figure 1. a) 3D schematic view of the APE-SCVD injection head (inset: a photograph of the 3D printed APE-SCVD head used in this work); b) a 2D simulation obtained by Comsol Multiphysics, showing the mixture of TVMS and Oxygen plasma in the gas phase just above the substrate. The substrate/injector gap was maintained at $500 \mu \mathrm{m}$ in this simulation, ${ }^{30}$ and the color bar corresponds to the zone where both TVMS and atomic oxygen are present; c) Variation of $\mathrm{SiO}_{2}$ film thickness as a function of high voltage applied to the DBD plasma source; d) Intensity variation of the oxygen atomic desexcitation peaks at $777 \mathrm{~nm}$ for different applied high voltages ranging from $7.8 \mathrm{kV}$ to $9.5 \mathrm{kV}$; e) FTIR spectra of a $45 \mathrm{~nm}$ thick $\mathrm{SiO}_{2}$ film deposited on a silicon substrate by APE-SCVD at $75{ }^{\circ} \mathrm{C}$; f) Si $2 \mathrm{p}$ core level XPS spectrum of $45 \mathrm{~nm}$ thick APE-SCVD $\mathrm{SiO}_{2}$ film deposited at $75^{\circ} \mathrm{C}$. 
with various oxidizing agents. Firstly, the surface adsorption activity of TVMS was tested by exposing it to microglass slides and two different silicon substrates (with and without extra plasma treatment,-see-experimental details) for $15 \mathrm{~min}$ at $100{ }^{\circ} \mathrm{C}$, using our SALD system. More details related to the reactivity tests using a standard SALD injection head can be found in the SI, Figure S2. If TVMS adsorption on these surfaces takes place, one would expect the surface to be terminated by hydrophobic groups, i.e. $-\mathrm{C}_{2} \mathrm{H}_{3}$ since the dissociation enthalpy of the $\mathrm{SiO}-\mathrm{CH}_{3}$ bond at $298 \mathrm{~K}(358$ $\mathrm{kJ} / \mathrm{mol})^{50}$ is much lower as compared to that of the $\mathrm{Si}-\mathrm{C}_{2} \mathrm{H}_{3}$ bond $(527 \mathrm{~kJ} / \mathrm{mol}) .{ }^{51}$ However, no difference in wettability of the substrates could be observed before and after exposure to TVMS. In addition, FTIR measurements (in the case of Si substrates) didn't show any trace of TVMS on the substrate surface, even for plasma treated substrates which contain a high density of $-\mathrm{OH}^{*}$ groups (see more details in the SI, Figure S1). This indicates that no TVMS adsorption happened under the test conditions, thus implying that TMVS is not a suitable ALD precursor, at least when working at atmospheric pressure.

As detailed above, our spatial system provides the possibility of intermixing precursor and co-reactant in the gas phase above the substrate surface by adjusting the gap between the head and the substrate (a scheme of a standard SALD head used in our system is shown in Figure S2 in the $\mathrm{SI})$. Thus, we explored the use of conventional oxidizers, namely $\mathrm{H}_{2} \mathrm{O}, \mathrm{H}_{2} \mathrm{O}_{2}$ and ozone, to test whether a SCVD growth mode leading to silicon dioxide deposition could be obtained using TVMS. In this case, no film growth was observed neither on glass nor on both standard and plasmatreated silicon substrates, thus confirming again the limited reactivity of TVMS against these co-reactants at atmospheric pressure and low temperatures $\left(<260^{\circ} \mathrm{C}\right)$. In view of these results, the use of plasma assistance was explored, since a variety of highly reactive radicals are formed, among which atomic oxygen $\left(\mathrm{O}^{*}\right)$ can be used as an efficient oxidizing agent to react with TVMS. Figure 1a shows a 3D schematic drawing of the APE-SCVD reactor used, which was fabricated by 3D printing (see inset). Taking advantage of the possibilities offered by 3D printing, we could design both the oxygen plasma generator and the TVMS gas delivering outlet in a single one-block head. Figure $1 \mathrm{~b}$ illustrates the result of a 2D simulation performed using Comsol Multiphysics (see more details in part 4 of the SI). It shows the mixture of TVMS and oxygen plasma in the gas phase above the substrate surface as a result of an increased deposition gap of $500 \mu \mathrm{m}$ (an oscillation speed of approximately $3 \mathrm{~cm} / \mathrm{s}$ was considered). The colored zone shown in Figure $1 \mathrm{~b}$ represents the concentration of the TVMS/oxygen plasma mixture in the gas phase at room temperature. The so-called CVD reaction zone corresponding to the volume of mixture can actually be simply monitored by adjusting the injection head-substrate gap. Similar to SALD, the thin film deposition is then obtained by exposing this CVD reaction zone to the substrate that moves underneath the precursor injector.

Figure 1c shows a tremendous increase in $\mathrm{SiO}_{2}$ film thickness from $22 \mathrm{~nm}$ to $152 \mathrm{~nm}$ (for the same deposition duration) when the high voltage applied to the DBD varies from $7.75 \mathrm{kV}$ to $10 \mathrm{kV}$, while all other experimental parameters such as carrier gas flow of TVMS $(100 \mathrm{sccm})$, substrate temperature $\left(180{ }^{\circ} \mathrm{C}\right)$ or the substrate/gas injector gap (150 $\mu \mathrm{m})$ are maintained constant. This can be taken as an indication that the film growth rate is proportional to the concentration of atomic oxygen generated. This assertion is supported by OES measurements shown in Figure 1d, in which an increase in the intensity of the atomic oxygen characteristic triplet $(777.19 \mathrm{~nm}, 777.42 \mathrm{~nm}$ and 777.54 $\mathrm{nm})^{52}$ with the applied high voltage is clearly observed. It should be also noted that, even though the oxygen plasma is generated in open-air conditions, no emission from nitrogen species were observed in the plasma when pure oxygen was flown through the DBD (200 sccm). This proves that the DBD integrated 3D printing gas injector used in this work is very efficient to prevent nitrogen contamination in the plasma (further details can be found in Figure S3a in the SI). Consistently, FTIR and XPS spectra of a $45 \mathrm{~nm}$ thick $\mathrm{SiO}_{2}$ sample (grown by APE-SCVD at $75^{\circ} \mathrm{C}$ using $10 \mathrm{kV}$ and $8 \mathrm{kHz}$ for plasma generation) do not show any trace of silicon nitride or carbide, as shown in Figure 1e-f. Si-O-Si peaks only can be detected, which are located at 1062 and $1130 \mathrm{~cm}^{-1}$ in the FTIR spectrum, and at $103.4 \mathrm{eV}$ in the XPS one $\left(\mathrm{SiN}_{\mathrm{x}}\right.$ peaks are located in the $900-950 \mathrm{~cm}^{-1}$ FTIR spectral region, and at $101.8 \mathrm{eV}$ in XPS spectra, ${ }^{53}$ while $\mathrm{SiC}_{\mathrm{x}}$ peaks are at about $760 \mathrm{~cm}^{-1}$ and $100.5 \mathrm{eV}$, respectively, in FTIR and XPS spectra). ${ }^{54}$ This remarkable observation demonstrates the possibility of using APE-SCVD and TVMS as silicon precursor to produce $\mathrm{SiO}_{2}$ at low temperature in ambient condition, leading to thin films with low carbon and nitrogen contaminations. In view of this result, it is expected that the deposition of nitride films such as $\mathrm{SiN}_{\mathrm{x}}$ could be achieved using open-air spatial approaches with a nitrogen DBD plasma.
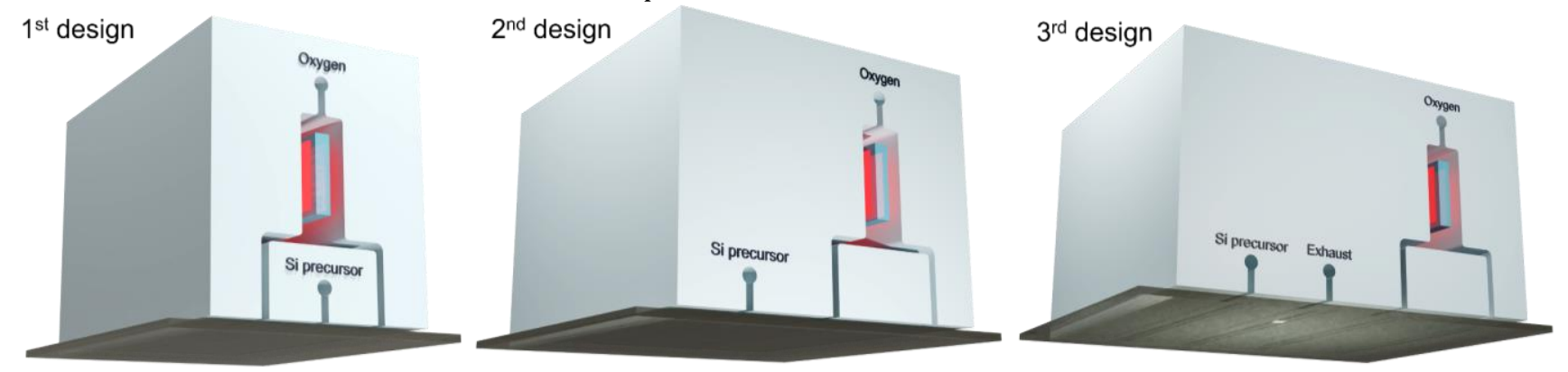

Figure 2. Three designs of APE-SCVD head with various distances between the oxygen plasma and TVMS output channel: 2 mm (left), $6 \mathrm{~mm}$ (middle) and $12 \mathrm{~mm}$ (right). An exhaust channel was added to the $3^{\text {rd }}$ case to further reduce the CVD mixture volume. 
In the plasma activated spatial CVD mode used here, a separation effect between the precursor and plasma outlets should be expected, given that plasma species have a short lifetime. Figure 2 shows three schematic designs of 3 different deposition heads with varying distance values between the oxygen plasma and the TVMS ( $2 \mathrm{~mm}, 6 \mathrm{~mm}$ and $12 \mathrm{~mm}$ ) output channels. In the third one, an exhaust channel was also present between the TVMS and plasma outlets, as is the case in typical SALD heads.

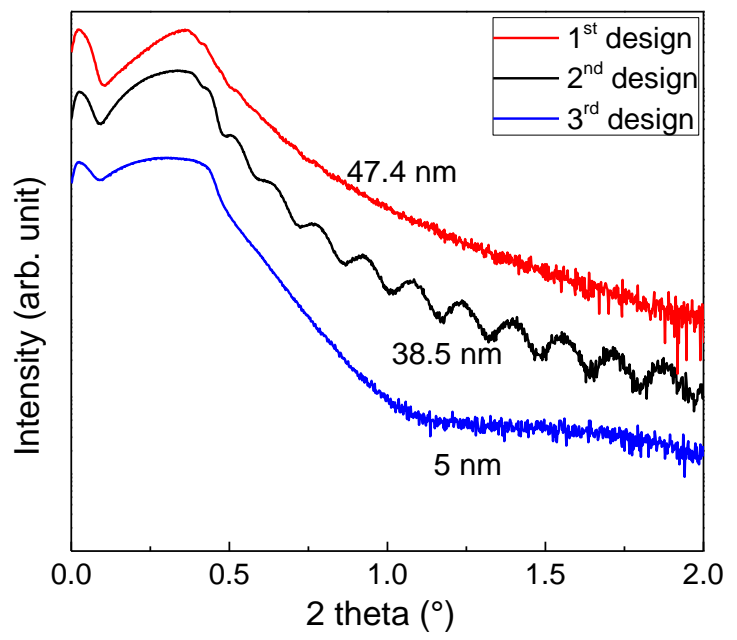

Figure 3. XRR patterns of $\mathrm{SiO}_{2}$ samples prepared by APE-SCVD at $75^{\circ} \mathrm{C}$ using different designs. The distance between the head and the substrate was maintained at $150 \mu \mathrm{m}$.

Figure 3 shows the XRR patterns of $\mathrm{SiO}_{2}$ films deposited under identical conditions of gas flows and temperature (75 ${ }^{\circ} \mathrm{C}$ ) using these different heads. Using the first two heads results in thin films with rather similar thickness, $47.4 \pm 0.5$ $\mathrm{nm}$ and $38.5 \pm 0.5 \mathrm{~nm}$, respectively. Despite yielding the thickest films, the first head design leads to rough films $(0.40 \pm 0.25 \mathrm{~nm}$ of roughness), as indicated by the absence of oscillation in the pattern. This can be explained by the fact that the concentration of oxygen atoms right at the two outlets is high, with the TVMS outlet located right next to them, making the CVD reaction very efficient. The second head design yielded films with a smoother surface $(0.17 \pm 0.1 \mathrm{~nm}$ of roughness), as indicated by the clear oscillations in the XRR pattern. Finally, the third design with a large distance between the TMVS and the oxygen plasma outlets, along with the addition of an exhaust channel, resulted in very thin $\mathrm{SiO}_{2}$ film $(5 \pm 0.2 \mathrm{~nm})$. This can actually be explained by the fact that the concentration of atomic oxygen decreases when travelling from the oxygen plasma outlets to the TMVS one. For this work, only the samples shown in the part concerning the effect of DBD voltage were deposited using the first injector design, while all other samples were deposited using the second one. In conventional CVD, a higher deposition temperature usually leads to a higher growth rate due to a more efficient decomposition of CVD precursors. However, in our case the film thickness significantly decreases when slightly increasing the deposition temperature (see Figure 4). Indeed, the decay processes of atomic oxygen such as $\mathrm{O}+\mathrm{O}+\mathrm{N}_{2} \rightarrow \mathrm{O}_{2}+\mathrm{N}_{2}$ or $\mathrm{O}+\mathrm{O}+$ surface $\rightarrow \mathrm{O}_{2}$ are temperature-dependent. The relationship between

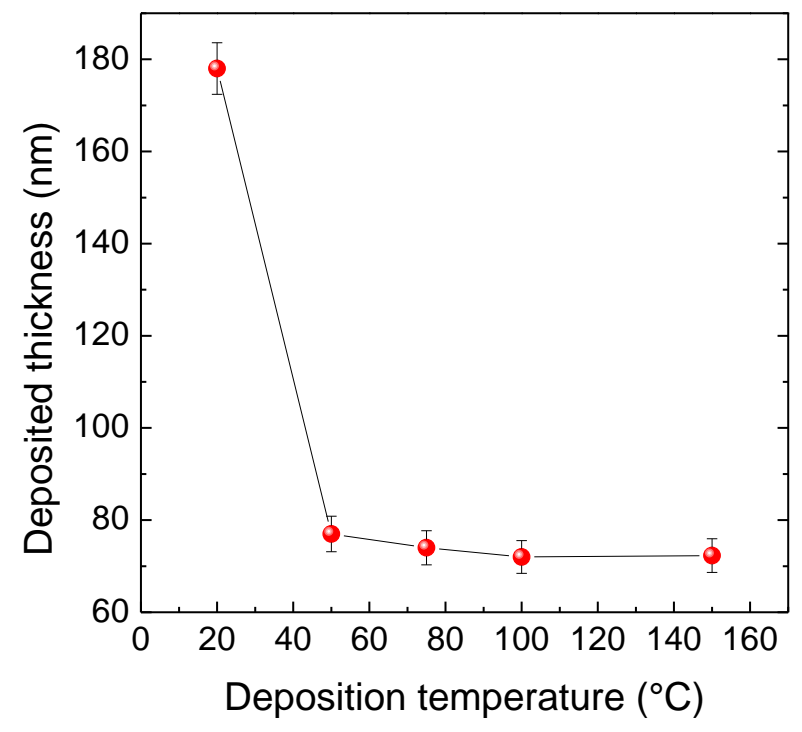

Figure 4. $\mathrm{SiO}_{2}$ film thickness as a function of deposition temperature. In this experiment, the values of plasma frequency, high voltage and deposition duration were $8 \mathrm{kHz}, 10 \mathrm{kV}$ and 5 min, respectively. The inset image is a Comsol Multiphysics simulation of the temperature variation in the gas channel, the substrate temperature was fixed at $100^{\circ} \mathrm{C}$.

the recombination coefficient for oxygen atoms and substrate temperature has been experimentally addressed in several works, for instance Greaves \& Linnette, ${ }^{55}$ and Brovikova. ${ }^{56}$ In these studies, an increase of the recombination coefficient for oxygen atoms was observed when the surface temperature varies from $20^{\circ} \mathrm{C}$ to $150{ }^{\circ} \mathrm{C}$. Therefore, a higher substrate temperature would lead to a decrease in the oxygen atom concentration, which agrees with the temperature-dependent growth rate of $\mathrm{SiO}_{2}$ films observed in our case.

In addition to the growth rate, the substrate temperature also has an impact on the chemical composition of the deposited films. Figure 5 a shows FTIR spectra of $\mathrm{SiO}_{2}$ films deposited with our APE-SCVD system at different substrate temperatures, varying from RT to $150^{\circ} \mathrm{C}$. Figure $5 \mathrm{~b}$ shows a normalized close-up of these spectra from $720 \mathrm{~cm}^{-1}$ to 1600 $\mathrm{cm}^{-1}$. Carbon contamination is usually found in $\mathrm{SiO}_{2}$ films prepared by CVD techniques, mainly originating from the organic nature of CVD precursors and uncompleted chemical reactions leading to $\mathrm{SiO}_{2}$ film formation. ${ }^{57-59} \mathrm{But}$ in our case, it is remarkable that neither $\mathrm{Si}-\mathrm{CH}_{\mathrm{x}}$ nor $\mathrm{Si}-\mathrm{N}$ groups are observed, even at deposition temperatures as low as RT and in open-air conditions. This means that all carbon species are efficiently removed during the APE-SCVD process thanks to the high reactivity of the close-proximity oxygen plasma. For the film deposited at RT, small $\mathrm{C}-\mathrm{H}$ and $\mathrm{C}=\mathrm{O}$ peaks are observed, which can be attributed to residues of TVMS or by-products from the reaction between atomic oxygen and TVMS. Moreover, when deposition is performed at low temperatures, $\mathrm{Si}-\mathrm{OH}$ group formation and water absorption from the atmosphere may also increase the intensity of $\mathrm{Si}-\mathrm{OH}$ and $\mathrm{H}-\mathrm{OH}$ peaks located at wavenumbers around $928 \mathrm{~cm}^{-1}$ and $3400 \mathrm{~cm}^{-1}$. While temperature clearly affects the quality of the deposited films, the plasma power 
had no sensible effect on FTIR spectra (see more details in Figure S3c-d of the SI).

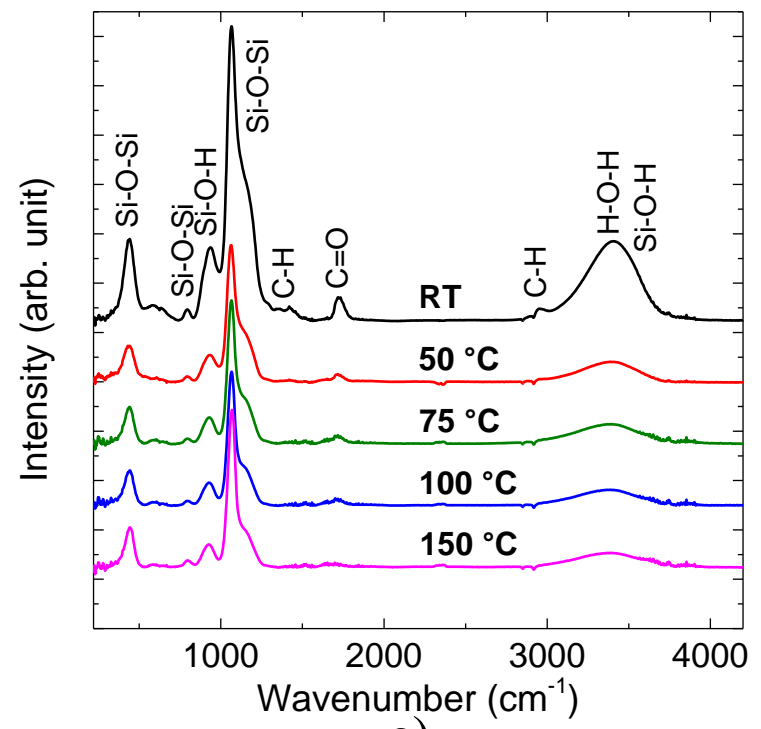

a)

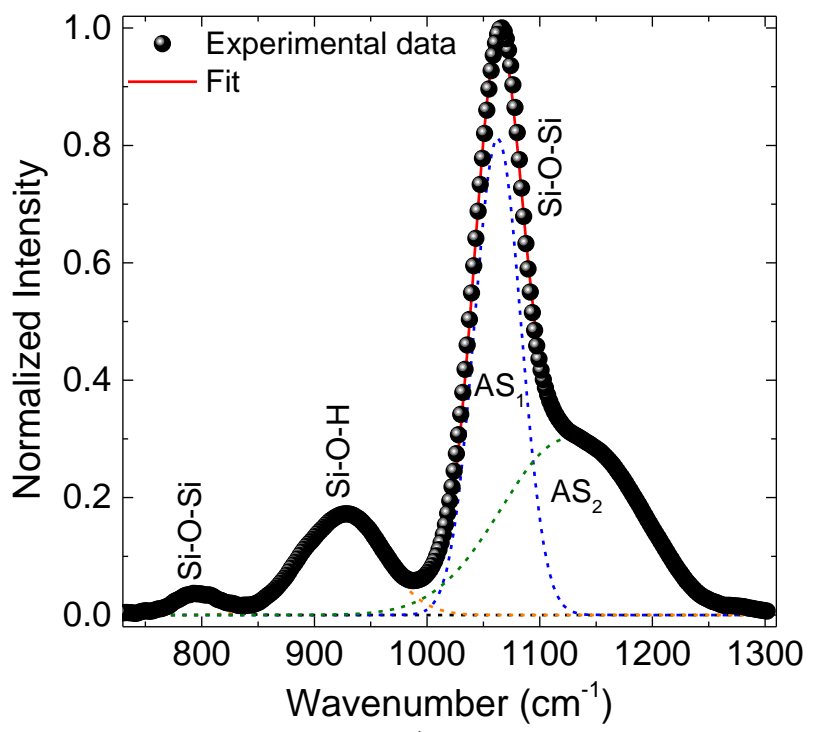

c)

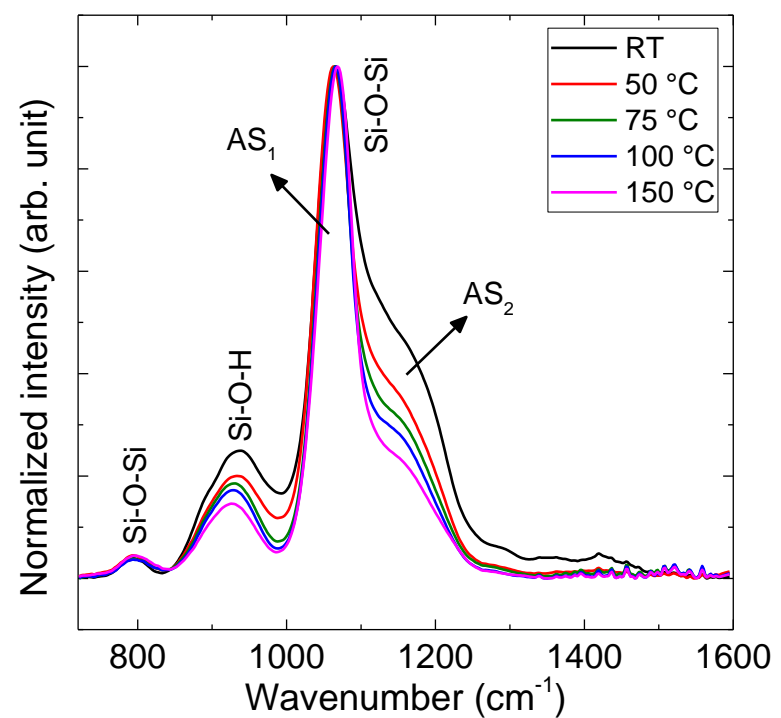

b)

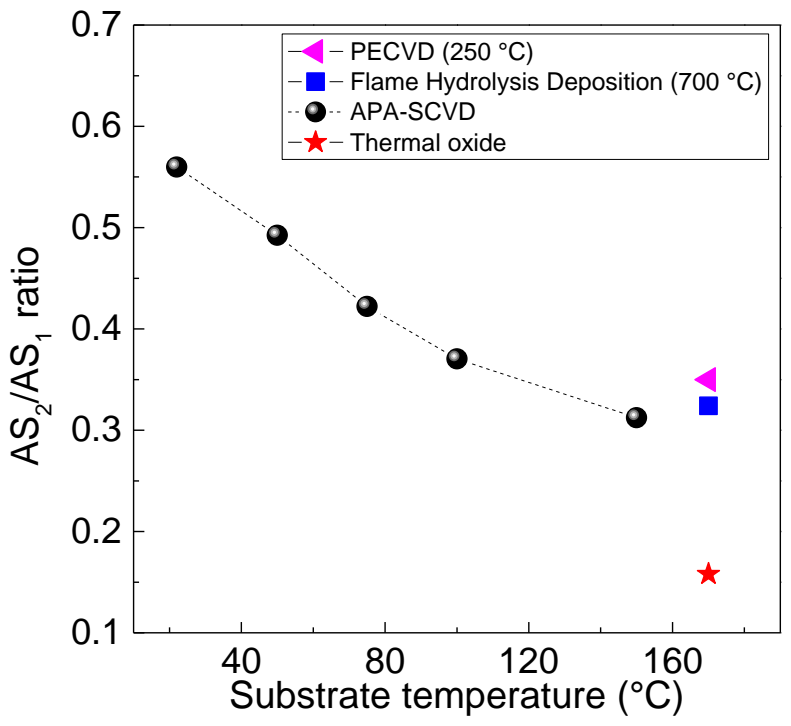

d)

Figure 5. a) FTIR spectra of $\mathrm{SiO}_{2}$ samples prepared at various substrate temperatures, b-c) a zoom into the main Si-O peaks of the normalized spectra shown in Figure 5a, and an example of fitting the main peaks with different components: Si-O-Si transverse optical asymmetric stretch with adjacent 0 atoms in phase $\left(\mathrm{AS}_{1}\right)$, and with adjacent 0 atoms out of phase $\left(\mathrm{AS}_{2}\right)$, d) comparison of the $\mathrm{AS}_{2} / \mathrm{AS}_{1}$ ratio of APE-SCVD samples with $\mathrm{SiO}_{2}$ samples prepared by other techniques. ${ }^{\mathbf{6 0 , 4 1}} \mathrm{SiCl}_{4}$ was used for $\mathrm{SiO}_{2}$ deposition by PECVD and Flame Hydrolysis Deposition.

A closer analysis in the $\left[720 \mathrm{~cm}^{-1}, 1600 \mathrm{~cm}^{-1}\right]$ region containing the main $\mathrm{Si}-\mathrm{O}-\mathrm{Si}$ peaks is shown in Figure $5 \mathrm{~b}$ and Figure 5c. The Si-O-Si transverse optical asymmetric stretch with adjacent $\mathrm{O}$ atoms in phase and with adjacent $\mathrm{O}$ atoms out of phase generates the two main peaks $\mathrm{AS}_{1}$ and $\mathrm{AS}_{2}$, respectively. The ratio of these peaks can be used as an index of the density and stoichiometry of the $\mathrm{SiO}_{2}$ films. Indeed, a lower $\mathrm{AS}_{2} / \mathrm{AS}_{1}$ ratio corresponds to a higher quality of $\mathrm{SiO}_{2}$ films (denser and stoichiometry closer to 1:2). Figure $5 \mathrm{~d}$ shows a comparison of the ratio of our APE-SCVD samples deposited at various substrate temperatures with the ratios calculated for samples prepared by other techniques. ${ }^{60,41}$ Firstly, the $\mathrm{AS}_{2} / \mathrm{AS}_{1}$ ratio decreases from 0.56 to 0.31 when the deposition temperature increases from RT to $150{ }^{\circ} \mathrm{C}$.
The value of the $\mathrm{AS}_{2} / \mathrm{AS}_{1}$ ratio of thermal $\mathrm{SiO}_{2}$ is 0.16 , while it is estimated to be about $0.35,0.33$ for samples prepared by PECVD, ${ }^{60}$ and flame hydrolysis deposition ${ }^{41}$ using $\mathrm{SiCl}_{4}$ at relatively high temperatures $\left(250{ }^{\circ} \mathrm{C}-700^{\circ} \mathrm{C}\right)$, and 0.31 for sample deposited by APE-SCVD at $150{ }^{\circ} \mathrm{C}$. Thus, our films have a quality that is comparable to films deposited by CVD at similar temperatures, or by flame hydrolysis at $700{ }^{\circ} \mathrm{C}$. It should also be noted that the quality of as-deposited $\mathrm{SiO}_{2}$ films by APE-SCVD can be further improved by a simple thermal annealing at $300-400{ }^{\circ} \mathrm{C}$ (see more details in Figure S4 of the SI). 
One of the main advantages of the SCVD concept is the ability of localizing the CVD reaction zone, i.e. the mixture volume between metalorganic precursor and oxidizing agent. As previously shown in Figure $1 \mathrm{~b}$, this CVD reaction zone is

$0.3 \mathrm{~mol} / \mathrm{m}^{3}$
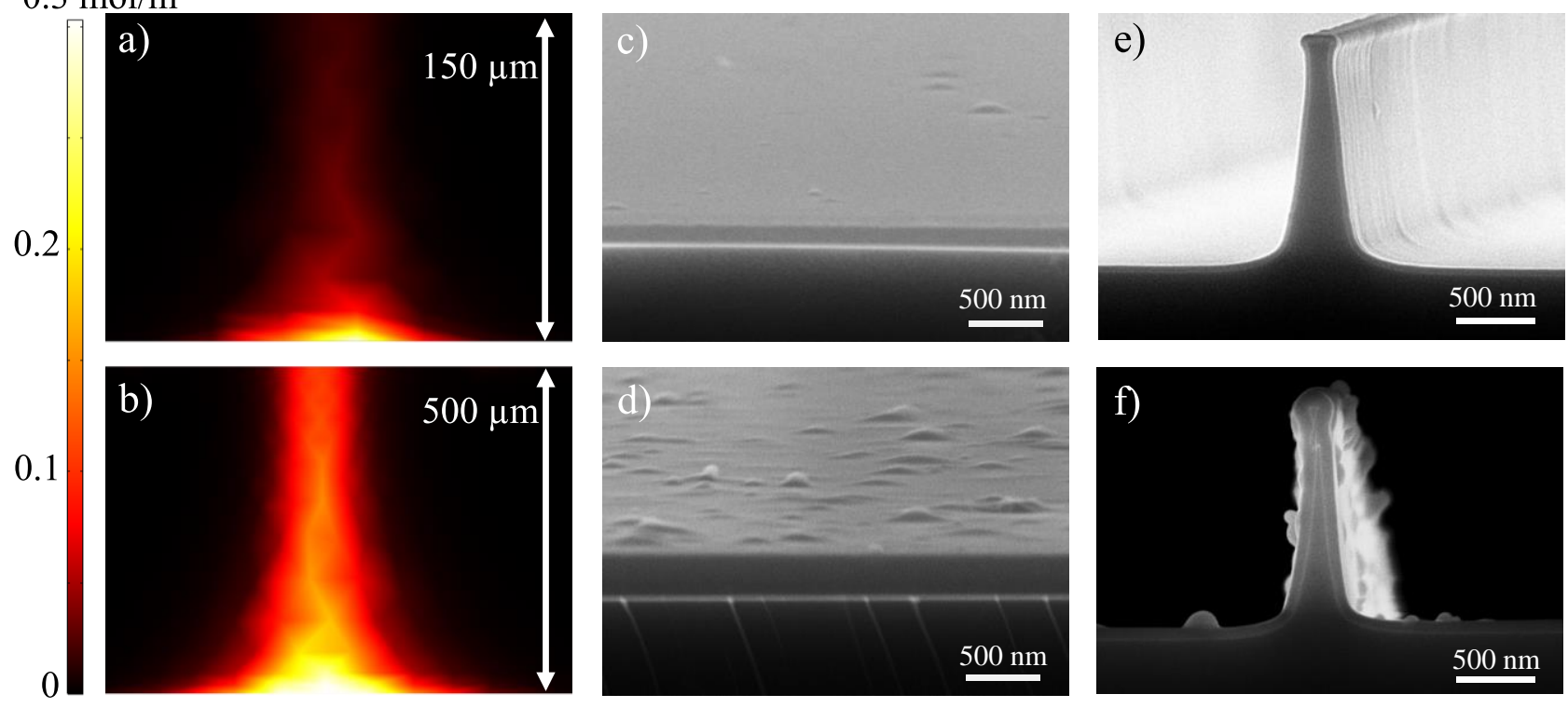

Figure 6. a) and b): simulation images of the CVD reaction zone obtained from 2D Comsol Multiphysics for two values of the injector/substrate gap $(150 \mu \mathrm{m}$ and $500 \mu \mathrm{m})$, the color intensity indicates the concentration of TVMS and atomic oxygen co-existing in the gap; c) and d): SEM micrographs of $\mathrm{SiO}_{2}$ thin film deposited on glass substrates using two values of the gap, $150 \mu \mathrm{m}$ and $500 \mu \mathrm{m}$, respectively. Samples were prepared at $50{ }^{\circ} \mathrm{C}$; e) and f) SEM micrographs of $\mathrm{SiO}_{2}$ thin coating deposited on patterned silicon substrates using two values of the gap, $150 \mu \mathrm{m}$ and $500 \mu \mathrm{m}$, respectively. Samples were prepared at $75^{\circ} \mathrm{C}$.

indeed a small area localized within the gap between the gas injector and the heated substrate. Thanks to an appropriate design of the gas injector, and by a careful adjustment of the distance between the injector and the substrate, as well as the other deposition parameters, the size of this 'virtual CVD chamber' can be easily monitored. Figure $6 \mathrm{a}$ and Figure $6 \mathrm{~b}$ show simulation images of the CVD reaction zone obtained using 2D Comsol Multiphysics for two values of injectorsubstrate gaps of $150 \mu \mathrm{m}$ and $500 \mu \mathrm{m}$, respectively. As can be observed, the mixture volume of TVMS and atomic oxygen is clearly larger and more efficient, as evidenced by a deeper color intensity, at larger substrate-injector gap (500 $\mu \mathrm{m})$, which means that for a constant precursor concentration at the inlet, a higher TVMS-to-SiO 2 conversion efficiency should be found. Interestingly, SEM micrographs of $\mathrm{SiO}_{2}$ deposited on glass substrates using these two gap values show a clear difference in the deposited film thickness, i.e. $145 \mathrm{~nm}$ versus $290 \mathrm{~nm}$, as shown in Figure 6c and Figure 6d. In contrast, although the higher gap value roughly yields twice as large as growth per cycle, the obtained films are rather rough with visible co-deposited particles. A similar situation was also observed when high-aspect-ratio features, such as patterned silicon substrates, were coated with $\mathrm{SiO}_{2}$ thin layers, as shown in Figure 6e and Figure 6f. Accordingly, using the higher substrate-injector gap, i.e. $500 \mu \mathrm{m}$, yields a $87 \mathrm{~nm}$-thick coating layer, along with the presence of particles, while using the closer gap allows depositing a highly conformal, $45 \mathrm{~nm}$-thick layer without any visible co-deposited nanoparticles. In both cases, the deposition is highly conformal. This result can be attributed to the large vertical distribution of the TVMS/atomic oxygen mixture in the case of larger gap, which leads to nanoparticle formation in the gas phase that may then be deposited over the thin film. For this reason, a thinner CVD mixture zone, or in other words, a smaller gap between the gas injector and the substrate, should generate a better film quality. Nevertheless, one can adjust the deposition parameters in the APE-SCVD system as a function of the targeted application, to produce highquality, smooth films or higher coating rates when roughness is not an issue.

\section{Conclusion}

In summary, we have demonstrated in this work the possibility of growing $\mathrm{SiO}_{2}$ thin films at low temperatures (RT $180{ }^{\circ} \mathrm{C}$ ), in open-air conditions using the atmospheric plasma-enhanced spatial chemical vapor deposition (APESCVD) technique. Taking advantage of the 3D printing technology, both precursor injector and the plasma generator were integrated into a single head, which is then placed at very close distance $(150-500 \mu \mathrm{m})$ to the substrate. This provides a very efficient supply of highly reactive chemical species (atomic oxygen in this case) to activate the CVD reaction on the substrate surface. We have shown that $\mathrm{SiO}_{2}$ deposition is not possible at temperatures up to $260{ }^{\circ} \mathrm{C}$ using TVMS as silicon precursor and $\mathrm{H}_{2} \mathrm{O}, \mathrm{H}_{2} \mathrm{O}_{2}$ or $\mathrm{O}_{3}$ as co-reactant. However, $\mathrm{SiO}_{2}$ deposition was successful when combining TVMS with an oxygen plasma containing highly reactive atomic oxygen. Our experimental results show that 
compact, conformal, pinhole-free $\mathrm{SiO}_{2}$ thin films can be deposited with a high growth rate of 2 up to $5 \mathrm{~nm} / \mathrm{min}$ on different substrates including silicon, glass and polymeric substrates. The APE-SCVD technique leads to $\mathrm{SiO}_{2}$ thin films with non-detectable $\mathrm{SiN}_{\mathrm{x}}$ or $\mathrm{SiC}_{\mathrm{x}}$ contamination levels, as confirmed by XPS or FTIR measurements, despite the use of a metalorganic precursor and low processing temperatures. Our findings open up a new approach for the deposition of functional thin films with a larger choice of available precursors and lower input thermal energy budget.

\section{ASSOCIATED CONTENT}

\section{Supporting Information.}

\section{AUTHOR INFORMATION}

\section{Corresponding Author}

* Corresponding authors:

huong.nguyenviet@phenikaa-uni.edu.vn

david.munuz-rojas@grenoble-inp.fr

Notes

The authors declare no competing financial interest.

\section{ACKNOWLEDGMENT}

This work was funded by the Agence Nationale de Recherche (ANR, France) via the programs ANR-16-CE05-0021 (DESPATCH), ANR-17-CE05-0034 (OXYGENE), and the "Investissements d'avenir" program (ANR-15-IDEX-02) through the project Eco-SESA. D.M.-R. also acknowledges support from the European Union's Horizon 2020 FETOPEN-1-2016-2017 research and innovation program under grant agreement 801464. Funding from the University Grenoble Alpes is acknowledged through the AGIR POLE 2016 program under the grant SURPASS. This work was benefited from funding from the Consejo Nacional de Ciencia y Tecnología (CONACYT) from Mexico (No. 456558). The authors acknowledge the Consortium des Moyens Technologiques Communs (CMTC)—Grenoble INP platform-for the characterization equipment.

\section{REFERENCES}

(1) Kim, D. H.; Lee, H. J.; Jeong, H.; Shong, B.; Kim, W.H.; Park, T. J. Thermal Atomic Layer Deposition of Device-Quality $\mathrm{SiO}_{2}$ Thin Films under $100^{\circ} \mathrm{C}$ Using an Aminodisilane Precursor. Chem. Mater. 2019, 31 (15), 5502-5508. https://doi.org/10.1021/acs.chemmater.9b01107.

(2) Kischkat, J.; Peters, S.; Gruska, B.; Semtsiv, M.; Chashnikova, M.; Klinkmüller, M.; Fedosenko, O.; Machulik, S.; Aleksandrova, A.; Monastyrskyi, G.; Flores, Y.; Ted Masselink, W. Mid-Infrared Optical Properties of Thin Films of Aluminum Oxide, Titanium Dioxide, Silicon Dioxide, Aluminum Nitride, and Silicon $\begin{array}{llllll}\text { Nitride. Appl. Opt. } & \text { 2012, } & 51 & \text { (28), } & 6789 .\end{array}$ https://doi.org/10.1364/AO.51.006789.

(3) Chang, Y.-F.; Fowler, B.; Chen, Y.-C.; Chen, Y.-T.; Wang, Y.; Xue, F.; Zhou, F.; Lee, J. C. Intrinsic SiOx-Based Unipolar Resistive Switching Memory. II. Thermal Effects on Charge Transport and Characterization of Multilevel Programing. J. Appl. Phys. 2014, 116 (4), 043709. https://doi.org/10.1063/1.4891244.
(4) O’Neal, H. E.; Ring, M. A.; Martin, J. G. Chemical Vapor Deposition (CVD) of Silicon Dioxide Films Using Oxygen-Silicon Source Reactants and a Free Radical Promoter. US5637351A 1997.

(5) Fujino, K.; Nishimoto, Y.; Tokumasu, N.; Maeda, K. Silicon Dioxide Deposition by Atmospheric Pressure and Low-Temperature CVD Using TEOS and Ozone. J. Electrochem. Soc. 1990, 137 (9), 2883-2887. https://doi.org/10.1149/1.2087093.

(6) Patrick, W. J.; Schwartz, G. C.; Chapple-Sokol, J. D.; Carruthers, R.; Olsen, K. Plasma-Enhanced Chemical Vapor Deposition of Silicon Dioxide Films Using Tetraethoxysilane and Oxygen: Characterization and Properties of Films. J. Electrochem. Soc. 1992, 139 (9), 2604-2613. https://doi.org/10.1149/1.2221272. (7) Mallick, A. B.; Nemani, S. D.; Yieh, E. High Quality Silicon Oxide Films by Remote Plasma CVD from Disilane Precursors. US Pat. No 7867923 2011, 17.

(8) Ho, S.-S.; Rajgopal, S.; Mehregany, M. Thick PECVD Silicon Dioxide Films for MEMS Devices. Sens. Actuators Phys. 2016, 240, 1-9. https://doi.org/10.1016/j.sna.2016.01.003.

(9) Bachmann, J.; Zierold, R.; Chong, Y. T.; Hauert, R.; Sturm, C.; Schmidt-Grund, R.; Rheinländer, B.; Grundmann, M.; Gösele, U.; Nielsch, K. A Practical, Self-Catalytic, Atomic Layer Deposition of Silicon Dioxide. Angew. Chem. Int. Ed. 2008, 47 (33), 6177-6179. https://doi.org/10.1002/anie.200800245.

(10) Karg, M.; Lokare, K. S.; Limberg, C.; Clavel, G.; Pinna, N. Atomic Layer Deposition of Silica on Carbon Nanotubes. Chem. Mater. 2017, 29 (11), 4920-4931. https://doi.org/10.1021/acs.chemmater.7b01165.

(11) Ma, H.-P.; Yang, J.-H.; Yang, J.-G.; Zhu, L.-Y.; Huang, W.; Yuan, G.-J.; Feng, J.-J.; Jen, T.-C.; Lu, H.-L. Systematic Study of the SiOx Film with Different Stoichiometry by Plasma-Enhanced Atomic Layer Deposition and Its Application in $\mathrm{SiOx} / \mathrm{SiO} 2$ Super-Lattice. Nanomaterials 2019, $9 \quad$ (1), 55. https://doi.org/10.3390/nano9010055.

(12) Deal, B. E.; Grove, A. S. General Relationship for the Thermal Oxidation of Silicon. J. Appl. Phys. 1965, 36 (12), 37703778. https://doi.org/10.1063/1.1713945.

(13) Bhatt, V.; Chandra, S. Silicon Dioxide Films by RF Sputtering for Microelectronic and MEMS Applications. J. Micromechanics Microengineering 2007, 17 (5), 1066-1077. https://doi.org/10.1088/0960-1317/17/5/029.

(14) Poodt, P.; Cameron, D. C.; Dickey, E.; George, S. M.; Kuznetsov, V.; Parsons, G. N.; Roozeboom, F.; Sundaram, G.; Vermeer, A. Spatial Atomic Layer Deposition: A Route towards Further Industrialization of Atomic Layer Deposition. J. Vac. Sci. Technol. Vac. Surf. Films 2012, 30 (1), 010802. https://doi.org/10.1116/1.3670745.

(15) Musselman, K. P.; Uzoma, C. F.; Miller, M. S. Nanomanufacturing: High-Throughput, Cost-Effective Deposition of Atomic Scale Thin Films via Atmospheric Pressure Spatial Atomic Layer Deposition. Chem. Mater. 2016, 28 (23), 8443-8452. https://doi.org/10.1021/acs.chemmater.6b03077.

(16) Muñoz-Rojas, D.; Nguyen, V. H.; Huerta, C. M. de la; Jiménez, C.; Bellet, D. Spatial Atomic Layer Deposition. Chem. Vap. Depos. Nanotechnol. 2019. https://doi.org/10.5772/intechopen.82439.

(17) Muñoz-Rojas, D.; MacManus-Driscoll, J. Spatial Atmospheric Atomic Layer Deposition: A New Laboratory and Industrial Tool for Low-Cost Photovoltaics. Mater. Horiz. 2014, 1 (3), 314. https://doi.org/10.1039/c3mh00136a.

(18) Muñoz-Rojas, D.; Nguyen, V. H.; Masse de la Huerta, C.; Aghazadehchors, S.; Jiménez, C.; Bellet, D. Spatial Atomic Layer Deposition (SALD), an Emerging Tool for Energy Materials. Application to New-Generation Photovoltaic Devices and Transparent Conductive Materials. Comptes Rendus Phys. 2017, 18 (78), 391-400. https://doi.org/10.1016/j.crhy.2017.09.004. 
(19) Illiberi, A.; Grehl, T.; Sharma, A.; Cobb, B.; Gelinck, G.; Poodt, P.; Brongersma, H.; Roozeboom, F. Spatial-ALD of Transparent and Conductive Oxides. Meet. Abstr. 2013, MA2013-02 (24), 1872.

(20) Illiberi, A.; Scherpenborg, R.; Roozeboom, F.; Poodt, P. Atmospheric Spatial Atomic Layer Deposition of In-Doped ZnO. ECS J. Solid State Sci. Technol. 2014, 3 (5), P111-P114.

(21) Maydannik, P. S.; Plyushch, A.; Sillanpää, M.; Cameron, D. C.; Cameron, D. C. Spatial Atomic Layer Deposition : Performance of Low Temperature $\mathrm{H} 2 \mathrm{O}$ and $\mathrm{O} 3$ Oxidant Chemistry for Flexible Electronics Encapsulation Spatial Atomic Layer Deposition: Performance of Low Temperature $\mathrm{H} 2 \mathrm{O}$ and $\mathrm{O} 3$ Oxidant Chemistry for Flexible Electronics. J. Vac. Sci. Technol. A 2015, 33 (3), 031603. https://doi.org/10.1116/1.4914079.

(22) Hoffmann, L.; Theirich, D.; Pack, S.; Kocak, F.; Schlamm, D.; Hasselmann, T.; Fahl, H.; Räupke, A.; Gargouri, H.; Riedl, T. Gas Diffusion Barriers Prepared by Spatial Atmospheric Pressure Plasma Enhanced ALD. ACS Appl. Mater. Interfaces 2017, 9 (4), 4171-4176. https://doi.org/10.1021/acsami.6b13380.

(23) Franke, S.; Baumkötter, M.; Monka, C.; Raabe, S.; Caspary, R.; Johannes, H.-H.; Kowalsky, W.; Beck, S.; Pucci, A.; Gargouri, H. Alumina Films as Gas Barrier Layers Grown by Spatial Atomic Layer Deposition with Trimethylaluminum and Different Oxygen Sources. J. Vac. Sci. Technol. Vac. Surf. Films 2017, 35 (1), 01B117. https://doi.org/10.1116/1.4971173.

(24) Nguyen, V. H.; Resende, J.; Papanastasiou, D. T.; Fontanals, N.; Jiménez, C.; Muñoz-Rojas, D.; Bellet, D. Low-Cost Fabrication of Flexible Transparent Electrodes Based on Al Doped $\mathrm{ZnO}$ and Silver Nanowire Nanocomposites: Impact of the Network Density. Nanoscale 2019, 11 (25), 12097-12107. https://doi.org/10.1039/C9NR02664A.

(25) van den Bruele, F. J.; Smets, M.; Illiberi, A.; Creyghton, Y.; Buskens, P.; Roozeboom, F.; Poodt, P. Atmospheric Pressure Plasma Enhanced Spatial ALD of Silver. J. Vac. Sci. Technol. Vac. Surf. Films 2015, $33 \quad$ (1), 01A131. https://doi.org/10.1116/1.4902561.

(26) Hoffmann, L.; Theirich, D.; Schlamm, D.; Hasselmann, T.; Pack, S.; Brinkmann, K. O.; Rogalla, D.; Peters, S.; Räupke, A.; Gargouri, H.; Riedl, T. Atmospheric Pressure Plasma Enhanced Spatial Atomic Layer Deposition of $\mathrm{SnO} \times$ as Conductive Gas Diffusion Barrier. J. Vac. Sci. Technol. Vac. Surf. Films 2018, 36 (1), 01A112. https://doi.org/10.1116/1.5006781.

(27) Levy, D. H.; Freeman, D.; Nelson, S. F.; CowderyCorvan, P. J.; Irving, L. M. Stable ZnO Thin Film Transistors by Fast Open Air Atomic Layer Deposition. Appl. Phys. Lett. 2008, 92 (19), 192101. https://doi.org/10.1063/1.2924768.

(28) Hoye, R. L. Z.; Muñoz-Rojas, D.; Musselman, K. P.; Vaynzof, Y.; MacManus-Driscoll, J. L. Synthesis and Modeling of Uniform Complex Metal Oxides by Close-Proximity Atmospheric Pressure Chemical Vapor Deposition. ACS Appl. Mater. Interfaces 2015, 7 (20), 10684-10694. https://doi.org/10.1021/am5073589.

(29) Musselman, K. P.; Muñoz-Rojas, D.; Hoye, R. L. Z.; Sun, H.; Sahonta, S.-L.; Croft, E.; Böhm, M. L.; Ducati, C.; MacManus-Driscoll, J. L. Rapid Open-Air Deposition of Uniform, Nanoscale, Functional Coatings on Nanorod Arrays. Nanoscale Horiz. 2017, 2 (2), 110-117. https://doi.org/10.1039/C6NH00197A.

(30) Masse de la Huerta, C.; Nguyen, V. H.; Dedulle, J.-M.; Bellet, D.; Jiménez, C.; Muñoz-Rojas, D. Influence of the Geometric Parameters on the Deposition Mode in Spatial Atomic Layer Deposition: A Novel Approach to Area-Selective Deposition. Coatings 2019, 9 (1), 5. https://doi.org/10.3390/coatings9010005.

(31) Muñoz-Rojas, D.; Sun, H.; Iza, D. C.; Weickert, J.; Chen, L.; Wang, H.; Schmidt-Mende, L.; MacManus-Driscoll, J. L. HighSpeed Atmospheric Atomic Layer Deposition of Ultra Thin Amorphous $\mathrm{TiO}_{2}$ Blocking Layers at $100{ }^{\circ} \mathrm{C}$ for Inverted Bulk Heterojunction Solar Cells: AALD for Inverted Bulk Heterojunction Solar
Cells. Prog. Photovolt. Res. Appl. 2013, n/a-n/a. https://doi.org/10.1002/pip.2380.

(32) Ali, K.; Choi, K.-H.; Jo, J.; Lee, Y. W. High Rate Rollto-Roll Atmospheric Atomic Layer Deposition of Al 2 O 3 Thin Films towards Gas Diffusion Barriers on Polymers. Mater. Lett. 2014, 136, 90-94. https://doi.org/10.1016/j.matlet.2014.07.186.

(33) Sneh, O.; Wise, M. L.; Ott, A. W.; Okada, L. A.; George, S. M. Atomic Layer Growth of $\mathrm{SiO} 2$ on $\mathrm{Si}(100)$ Using $\mathrm{SiCl} 4$ and H2O in a Binary Reaction Sequence. Surf. Sci. 1995, 334 (1), 135152. https://doi.org/10.1016/0039-6028(95)00471-8.

(34) Ezhovskii, Yu. K.; Kholkin, V. Yu. Growth and Properties of A12O3 and $\mathrm{SiO} 2$ Nanolayers on III-V Semiconductors. Inorg. Mater. 2010, $46 \quad$ (1), 38-42. https://doi.org/10.1134/S0020168510010097.

(35) Lee, S.-W.; Park, K.; Han, B.; Son, S.-H.; Rha, S.-K.; Park, C.-O.; Lee, W.-J. Atomic Layer Deposition of Silicon Oxide Thin Films by Alternating Exposures to Si2Cl6 and O3. Electrochem. Solid State Lett. 2008, 11 (7), G23. https://doi.org/10.1149/1.2908201.

(36) Lee, J.-H.; Kim, U.-J.; Han, C.-H.; Rha, S.-K.; Lee, W.J.; Park, C.-O. Investigation of Silicon Oxide Thin Films Prepared by Atomic Layer Deposition Using $\mathrm{SiH} 2 \mathrm{Cl} 2$ and $\mathrm{O} 3$ as the Precursors. Jpn. J. Appl. Phys. 2004, 43 (3A), L328. https://doi.org/10.1143/JJAP.43.L328.

(37) Klaus, J. W.; George, S. M. Atomic Layer Deposition of $\mathrm{SiO} 2$ at Room Temperature Using NH3-Catalyzed Sequential Surface Reactions. Surf. Sci. 2000, 447 (1), 81-90. https://doi.org/10.1016/S0039-6028(99)01119-X.

(38) Du, Y.; Du, X.; George, S. M. Mechanism of PyridineCatalyzed SiO2 Atomic Layer Deposition Studied by Fourier Transform Infrared Spectroscopy. J. Phys. Chem. C 2007, 111 (1), 219-226. https://doi.org/10.1021/jp0638484.

(39) Shareef, I. A.; Rubloff, G. W.; Anderle, M.; Gill, W. N.; Cotte, J.; Kim, D. H. Subatmospheric Chemical Vapor Deposition Ozone/TEOS Process for SiO2 Trench Filling. J. Vac. Sci. Technol. B Microelectron. Nanometer Struct. Process. Meas. Phenom. 1995, 13 (4), 1888-1892. https://doi.org/10.1116/1.587830.

(40) Ferguson, J. D.; Smith, E. R.; Weimer, A. W.; George, S. M. ALD of $\mathrm{SiO} 2$ at Room Temperature Using TEOS and $\mathrm{H} 2 \mathrm{O}$ with NH 3 as the Catalyst. J. Electrochem. Soc. 2004, 151 (8), G528-G535. https://doi.org/10.1149/1.1768548.

(41) Bange, J. P.; Patil, L. S.; Gautam, D. K. Growth and Characterization of $\mathrm{SiO} 2$ Films Deposited by Flame Hydrolysis Deposition System for Photonic Device Application. Prog. Electromagn. Res. M 2008, 3, 165-175. https://doi.org/10.2528/PIERM08060401.

(42) Ponton, S.; Vergnes, H.; Samelor, D.; Sadowski, D.; Vahlas, C.; Caussat, B. Development of a Kinetic Model for the Moderate Temperature Chemical Vapor Deposition of SiO2 Films from Tetraethyl Orthosilicate and Oxygen. AIChE J. 2018, 64 (11), 3958-3966. https://doi.org/10.1002/aic.16222.

(43) Grill, A.; Patel, V. Low Dielectric Constant Films Prepared by Plasma-Enhanced Chemical Vapor Deposition from Tetramethylsilane. J. Appl. Phys. 1999, 85 (6), 3314-3318. https://doi.org/10.1063/1.369677.

(44) Fonash, S. J.; Lin, X.; Reber, D. M. Low Temperature, High Quality Silicon Dioxide Thin Films Deposited Using Tetramethylsilane (TMS) for Stress Control and Coverage Applications. US6531193B2, March 11, 2003.

(45) Shin, D.; Song, H.; Lee, M.; Park, H.; Ko, D.-H. PlasmaEnhanced Atomic Layer Deposition of Low Temperature Silicon Dioxide Films Using Di-Isopropylaminosilane as a Precursor. Thin Solid Films 2018, 660, 572-577. https://doi.org/10.1016/j.tsf.2018.05.033.

(46) Lee, Y.-S.; Choi, D.; Shong, B.; Oh, S.; Park, J.-S. Low Temperature Atomic Layer Deposition of SiO2 Thin Films Using 
Di-Isopropylaminosilane and Ozone. Ceram. Int. 2017, 43 (2), 2095-2099. https://doi.org/10.1016/j.ceramint.2016.10.186.

(47) Burton, B. B.; Kang, S. W.; Rhee, S. W.; George, S. M. $\mathrm{SiO}_{2}$ Atomic Layer Deposition Using Tris(Dimethylamino)Silane and Hydrogen Peroxide Studied by in Situ Transmission FTIR Spectroscopy. J. Phys. Chem. C 2009, 113 (19), 8249-8257. https://doi.org/10.1021/jp806638e.

(48) Zoubian, F.; Rabat, H.; Aubry, O.; Dumuis, N.; Dozias, S.; Muñozrojas, D.; Hong, D. Development and Characterization of an Atmospheric Pressure Plasma Reactor Compatible with Spatial ALD. J. Phys. Conf. Ser. 2019, 1243, 012002. https://doi.org/10.1088/1742-6596/1243/1/012002.

(49) Vajeeston, P.; Fjellvåg, H.; Nilsen, O. Search for Potential Precursors for Si-Atomic Layer Deposition - A Quantum Chemical Study. Mater. Lett. 2018, 216, 189-192. https://doi.org/10.1016/j.matlet.2018.01.040.

(50) Allendorf, M. D.; Melius, C. F.; Ho, P.; Zachariah, M. R. Theoretical Study of the Thermochemistry of Molecules in the SiO-H System. J. Phys. Chem. 1995, 99 (41), 15285-15293. https://doi.org/10.1021/j100041a052.

(51) Allendorf, M. D.; Melius, C. F. Theoretical Study of the Thermochemistry of Molecules in the Silicon-Carbon-Hydrogen System. J. Phys. Chem. 1992, 96 (1), 428-437. https://doi.org/10.1021/j100180a080.

(52) Milosavljević, V.; Ellingboe, A. R.; Daniels, S. Influence of Plasma Chemistry on Oxygen Triplets. Eur. Phys. J. D 2011, 64 (2-3), 437-445. https://doi.org/10.1140/epjd/e2011-20213-2.

(53) Diéguez, L.; Caballero, D.; Calderer, J.; Moreno, M.; Martínez, E.; Samitier, J. Optical Gratings Coated with Thin Si3N4 Layer for Efficient Immunosensing by Optical Waveguide Lightmode Spectroscopy. Biosensors 2012, 2 (2), 114-126. https://doi.org/10.3390/bios2020114.
(54) Sun, L.; Han, C.; Wu, N.; Wang, B.; Wang, Y. High Temperature Gas Sensing Performances of Silicon Carbide Nanosheets with an $\mathrm{n}-\mathrm{p}$ Conductivity Transition. RSC Adv. 2018 , 8 (25), 13697-13707. https://doi.org/10.1039/C8RA02164C.

(55) Greaves, J. C.; Linnett, J. W. Recombination of Atoms at Surfaces. Part 6.- Recombination of Oxygen Atoms on Silica from $20^{\circ} \mathrm{C}$ to $600^{\circ} \mathrm{C}$. Trans Faraday Soc 1959, 55 (0), 1355-1361. https://doi.org/10.1039/TF9595501355.

(56) Brovikova, I. N. The Kinetics of Production and Loss of $\mathrm{O}(3 \mathrm{P})$ Oxygen Atoms in Air Plasma. High Temp. 2004, 42 (6), 879-882. https://doi.org/10.1007/s10740-005-0031-6.

(57) Kim, H. J.; Shao, Q.; Kim, Y.-H. Characterization of Low-Dielectric-Constant SiOC Thin Films Deposited by PECVD for Interlayer Dielectrics of Multilevel Interconnection. Surf. Coat. Technol. 2003, 171 (1-3), 39-45. https://doi.org/10.1016/S02578972(03)00233-0.

(58) Kim, C. Y.; Kim, S. H.; Navamathavan, R.; Choi, C. K.; Jeung, W. Y. Characteristics of Low-k SiOC $(-\mathrm{H})$ Films Deposited at Various Substrate Temperature by PECVD Using DMDMS/O2 Precursor. Thin Solid Films 2007, 516 (2-4), 340-344. https://doi.org/10.1016/j.tsf.2007.06.097.

(59) Mori, T.; Masuko, T.; Shirakura, A.; Suzuki, T. Effects of Dilution Gas on Characteristics of $\operatorname{SiOC}(\mathrm{H})$ Films Synthesized by Atmospheric Pressure Plasma CVD. Surf. Coat. Technol. 2016, 307, 1065-1069. https://doi.org/10.1016/j.surfcoat.2016.07.028.

(60) Park, Y.-B.; Rhee, S.-W. Microstructure and Interfacial States of Silicon Dioxide Film Grown by Low Temperature Remote Plasma Enhanced Chemical Vapor Deposition. J. Appl. Phys. 1999, 86 (3), 1346-1354. https://doi.org/10.1063/1.370893. 


\section{Table of Contents}

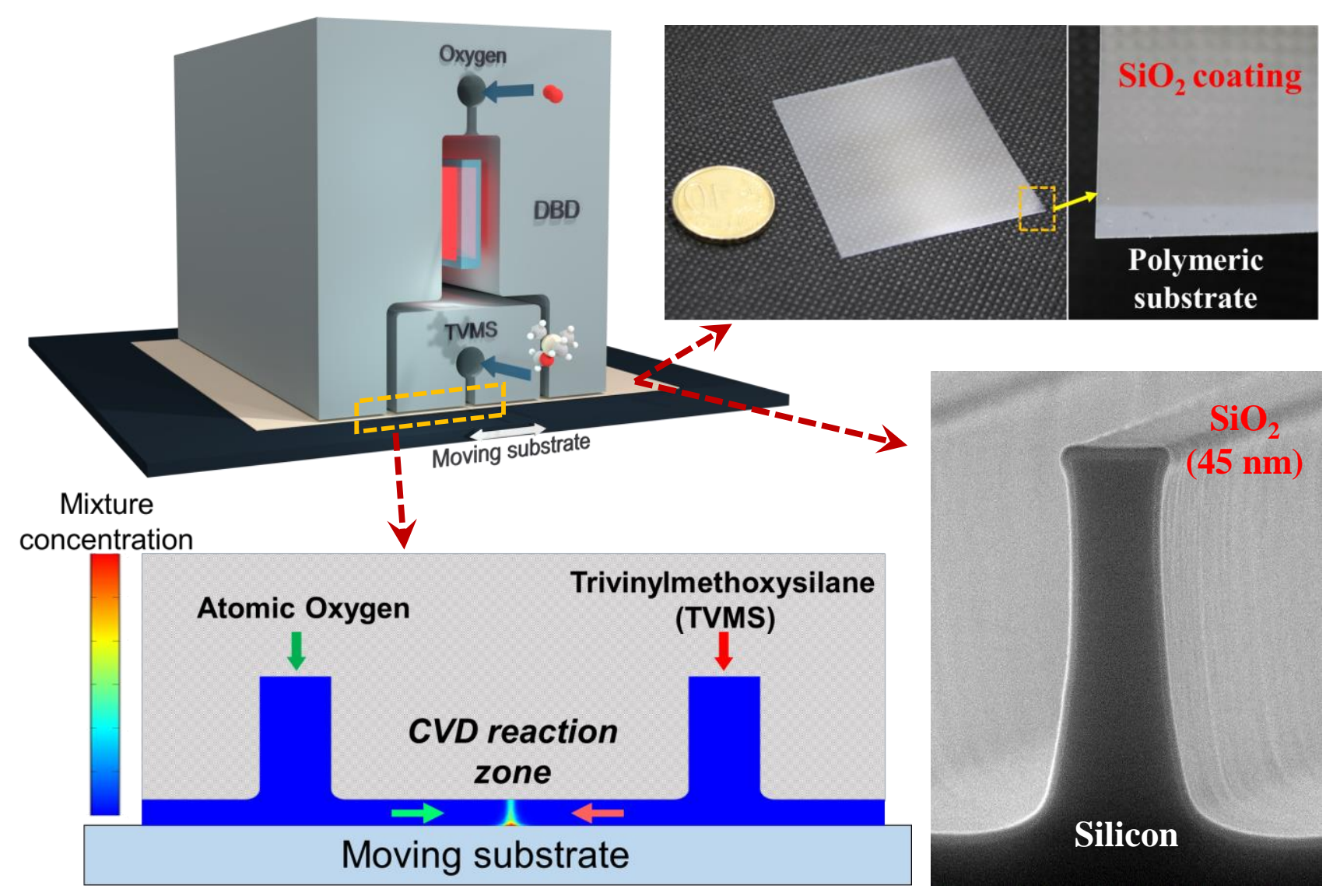

